\title{
ON FUZZY SUPRA PRE $\sigma$-BAIRE SPACES
}

\section{E.Poongothai ${ }^{1}$ and $G$. Thangaraj $^{2}$}

${ }_{1}^{1}$ Department of Mathematics, Shanmuga Industries Arts and Science College Tiruvannamalai - 632601, Tamilnadu, India. 2Department of Mathematics, Thiruvalluvar University Vellore - 632 115, Tamilnadu, India

ABSTRACT: In this paper, the concepts of fuzzy supra pre $\sigma$-nowhere dense set, fuzzy supra pre $\sigma$-first category set and fuzzy supra pre $\sigma$-second category set in fuzzy topological spaces are introduced and studied. By means of fuzzy supra pre $\sigma$ nowhere dense sets, the concept of fuzzy supra pre $\sigma$-Baire space is defined and several characterizations of fuzzy supra pre $\sigma$ Baire spaces are studied. Several examples are given to illustrate the concepts introduced in this paper.

KEYWORDS: Fuzzy supra pre dense set, fuzzy supra pre nowhere dense set, fuzzy supra pre F_o-set, fuzzy supra pre G_ $\delta$-set, fuzzy supra pre $\sigma$-nowhere dense set, fuzzy supra pre $\sigma$-first category, fuzzy supra pre $\sigma$-second category, fuzzy supra pre $\sigma$ Baire space.

(C) 2017 mahendrapublications.com, All rights reserved

\section{INTRODUCTION}

Dealing with the uncertainties in our real life phenomena has been a critical matter in recent years. Classical set theory was not suitable in such cases. Since 1965, Zadeh [1] has introduced a more suitable set theory providing the concept "fuzzy set". A large community of Mathematics has put their relentless efforts to the investigation of various concepts of general topology in fuzzy setting likely, [2-5]. In 2012, Selvi and Dharani, [6] introduced the concept of pre* open (supra - preopen) sets in general topology. In 2016, Hakeem A.Othman [7] introduced the concept of fuzzy supra pre open sets in supra topology. The concept of fuzzy supra $\sigma$-Baire spaces were introduced and studied by Poongothai and Thangaraj [8]. In this paper, the concepts of fuzzy supra pre $\sigma$-nowhere dense sets and fuzzy supra pre $\sigma$-Baire spaces are introduced and studied. Several characterizations of fuzzy supra pre $\sigma-$ Baire spaces are studied.

\section{PRELIMINARIES}

Definition 2.1 [8]: A fuzzy topology $\mathrm{T}$ on a set $\mathrm{X}$ is a family of fuzzy sets in $X$ such that

$0_{X}, 1_{X} \in T_{;}$

$A, B \in T \Rightarrow A \wedge B \in T$ and

$A_{i} \in T \Rightarrow V A_{i} \in T$

The pair $(X, T)$ is called a fuzzy topological space (FTS). The elements of $\mathrm{T}$ are called fuzzy open sets and the complement of fuzzy open set is called fuzzy closed set.

Definition 2.2 [4]: The closure and the interior of a fuzzy set A in FTS $(X, T)$ are denoted and defined respectively as

$C l(A)=\wedge\{B: A \leq B, B$ is a fuzzy closed set in $X\}$, $\operatorname{lnt}(A)=\mathrm{V}\{B: B \leq A, B$ is a fuzzy open set in $X\}$.
Definition 2.3[1]: A collection $T^{*}$ of fuzzy open sets in a set $\mathrm{X}$ is called a fuzzy supra topology on $\mathrm{X}$ if the following conditions are satisfied:

\section{(1) $0_{X}, 1_{X} \in T$ and (2) $A_{i} \in T \Rightarrow V A_{i} \in T$}

The pair $\left(X, T^{8}\right)$ is called a fuzzy supra topological space (FSTS). The elements of $T^{* 8}$ are called fuzzy supra open sets (FSOS) and the complement of a fuzzy supra open set is called fuzzy supra closed set (FSCS). The collection of all fuzzy supra open sets (resp.fuzzy supra closed sets) of the FSTS $\left(X, T^{*}\right)$ is denoted by FSOS(X) (resp. FSCS $(\mathrm{X})$ ).

Remark 2.4 (4):

Every FTS is a FSTS.

If $\left(X, T^{*}\right)$ is an associated FSTS with the FTS $(X, T)$ (i.e. $T \subseteq T^{8}$ ), then every fuzzy open (closed) set in the FTS $(X, T)$ is fuzzy supra open (closed) set in the FSTS $\left(X, T^{8}\right)$.

Definition 2.5 [7]: Let $\left(X, T^{*}\right)$ is a FSTS and A be fuzzy set in $X$, then the fuzzy supra closure and fuzzy supra interior are denoted and defined respectively as $C l^{*}(A)=\wedge\{B: A \leq B, B$ is a fuzzy supra closed set in $X\}$, $\ln t^{*}(A)=\mathrm{V}\{B: B \leq A, B$ is a fuzzy supra open set in $X\}$. Remark 2.6 [7]:

The fuzzy supra closure of a fuzzy set A in a FSTS is the smallest fuzzy supra closed set containing A.

The fuzzy supra interior of a fuzzy set A in a FSTS is the largest fuzzy supra open set containing in A.

If $\left(X, T^{*}\right)$ is an associated FSTS with the FTS $(X, T)$ and $A$ is any fuzzy set in $X$, then

$\operatorname{lnt}(A) \leq \operatorname{int}^{*}(A) \leq A \leq C l^{*}(A) \leq C l(A)$.

Properties of fuzzy supra closure and fuzzy supra interior which are needed in the sequel, are summarized in

*Corresponding Author: epoongothai5@gmail.com and g.thangaraj@rediffmail.com

Received: 25.09.2017 Accepted: 10.11.2017 Published on: 12.12.2017 
the following theorem

Theorem 2.7 [4]: For any fuzzy sets A and B in a FSTS $\left(X_{,} T^{8}\right)$.

$A \in F S C S(X) \Leftrightarrow C l^{*}(A)=A, A \in$

$\operatorname{FSOS}(X) \Leftrightarrow \operatorname{Int}{ }^{*}(A)=A$;

$A \leq B_{y} \Rightarrow C l^{*}(A) \leq$

$C l^{*}(B)$ and $\operatorname{Int}^{*}(A) \leq \operatorname{Int}^{*}(B)$;

$C l^{*}\left(C l^{*}(A)\right)=$

$C l^{*}(A)$ and $\operatorname{Int}^{*}\left(\operatorname{Int}^{*}(A)\right)=$

$\operatorname{Int}^{*}(A)$;

$C l^{*}(A \vee B) \geq C l^{*}(A) \vee C l^{*}(B) ;$

$C l^{*}(A \wedge B) \leq C l^{*}(A) \wedge C l^{*}(B)$;

$\ln t^{*}(A \vee B) \geq \operatorname{Int}^{*}(A) \vee \ln t^{*}(B)$;

$\operatorname{Int}(A \wedge B) \leq \operatorname{Int} t^{*}(A) \wedge \operatorname{Int}(B)$;

$C l^{*}\left(A^{C}\right)=\left(\operatorname{Int}^{*}(A)\right)^{C}{ }_{,} \operatorname{Int}^{*}\left(A^{C}\right)=$

$\left(C l^{*}(A)\right)^{C}$

Definition 2.8 [5] : A fuzzy set $\lambda$ of fuzzy space $X$ is called fuzzy supra preopen (supra preclosed) set if $\lambda \leq i n t^{*} \mathrm{cl} \lambda\left(\mathrm{cl}^{*}\right.$ int $\left.\lambda \leq \lambda\right)$. The class of all fuzzy supra-preopen ( supra - preclosed) sets in $X$ will as denoted be $\operatorname{SFPO}(X)(\operatorname{SFPC}(X))$.

Definition 2.9 [5] : The closure and the interior of a fuzzy set A in FTS $(X, T)$ are denoted and defined respectively as

$\operatorname{spCl}(A)=$

$\wedge$

$\{B: A \leq$

$B, B$ is a fuzzy supra preclosed set of $X\}$,

$\operatorname{sp} \operatorname{Int}(A)=\mathrm{V}\{B: B \leq A, B$ is a fuzzy supra pre open set of $X\}$.

Definition 2.10 [5] : Let A be a fuzzy supra set of a fuzzy supra topological space $(X, T)$. Then (i) $1-p c l^{*}(A)=\operatorname{pint}^{*}(1-A)(i i) 1-$ $\operatorname{pint}^{*}(A)=p c l^{*}(1-A)$
Defintion 2.11 [9]: A fuzzy set $\mathrm{A}$ in a $\operatorname{FSTS}\left(X, T^{*}\right)$ is called fuzzy supra $F_{\sigma}-$ set in $\left(X, T^{8}\right)$ if $A=\mathrm{V}_{i=1}^{\infty} A_{i}$, where $1-A_{i} \in T^{*}$ for $i \in I$.

Definition 2.12 [9]: A fuzzy set $\mathrm{A}$ in a $\operatorname{FSTS}\left(X, T^{8}\right)$ is called a fuzzy supra $G_{\delta}-\operatorname{set}$ in $\left(X, T^{*}\right)$ if $A=\Lambda_{i=1}^{\infty} A_{i}$, where $A_{i} \in T^{*}$ for $i \in I$.

Definition 2.13 [9]: Let $\left(X, T^{*}\right)$ be a fuzzy supra topological space. A fuzzy set $\mathrm{A}$ in $\left(X, T^{*}\right)$ is called a fuzzy supra $\sigma$-nowhere dense set if A is a fuzzy supra $F_{\sigma}-$ set in $\left(X, T^{*}\right)$ such that $\operatorname{lnt}^{*}(A)=0$.

Definition 2.14 [9]: Let $\left(X, T^{*}\right)$ be a fuzzy supra topological space. A fuzzy set $\mathrm{A}$ in $\left(X, T^{*}\right)$ is called fuzzy supra $\sigma$-first category if $A=V_{i=1}^{\infty}\left(A_{i}\right)$ where $\left(A_{i}\right)^{\prime} s$ are fuzzy supra $\sigma$-nowhere dense sets in $\left(X, T^{8}\right)$. Any other fuzzy set in $\left(X, T^{*}\right)$ is said to be fuzzy supra $\sigma$-second category in $\left(X, T^{8}\right)$.

3. FUZZY SUPRA PRE $\sigma$-NOWHERE DENSE SETS Definition 3.1: A fuzzy set A in a FSTS $\left(X, T^{*}\right)$ is called fuzzy supra pre dense if there exists no fuzzy supra pre closed set $\mathrm{B}$ in $\left(X, T^{*}\right)$ such that $A<B<1$. That is, $p C l^{*}(A)=1$.

Definition 3.2: A fuzzy set A in a FSTS $\left(X, T^{*}\right)$ is called fuzzy supra pre $F_{\sigma}$ - set in $\left(X_{,} T^{*}\right)$ if $A=\mathrm{V}_{i=1}^{\infty} A_{i}$ where $\left(A_{i}\right)$ 's are fuzzy supra pre-closed sets in $\left(X, T^{* 8}\right)$.

Definition 3.3: A fuzzy set A in a FSTS $\left(X, T^{*}\right)$ is called a fuzzy supra pre $G_{\delta}$ - set in $\left(X_{,} T^{*}\right)$ if $A=\Lambda_{i=1}^{\infty} A_{i}$, where $\left(A_{i}\right)$ 's are fuzzy supra pre-open sets in $\left(X, T^{*}\right)$.

Definition 3.4: A fuzzy set A in a FSTS $\left(X, T^{*}\right)$ is called fuzzy supra pre nowhere dense if there exists no non-zero fuzzy supra pre - open set $\mathrm{B}$ in $\left(X, T^{*}\right)$ such that $B<p c l^{*}(A)$. That is, $\operatorname{pint}^{*} p c l^{*}(A)=0$.

Definition 3.5: Let $\left(X, T^{*}\right)$ be a fuzzy supra topological space. A fuzzy set $\mathrm{A}$ in $\left(X, T^{8}\right)$ is called a fuzzy supra pre $\sigma$-nowhere dense set if $\mathrm{A}$ is a fuzzy supra pre $F_{\sigma}-$ set in $\left(X, T^{*}\right)$ such that pint ${ }^{*}(A)=0$.

Example 3.6: Let $X=\{a, b\}$ be a set with a fuzzy supra topology $\left(X, T^{*}\right)$. Then the fuzzy sets $A=\left\{a_{7_{7}}, b_{7}\right\}, B=\left\{a_{7_{7}}, b_{6}\right\}, c=\left\{a_{6}, b_{8}\right\}$. Then

\section{E.Poongothai \& G.Thangaraj,}


$T^{*}=\{0, A, B, C, A \cup B, B \vee C, B \wedge C, 1-$

$A, 1-B, 1-C, 1-A \vee B, 1-B \vee C, 1-B \wedge$

C,1\}

. Now, consider the fuzzy set $\alpha=(1-A \vee B) \vee(1-B \vee C) \vee(1-B \wedge C)$

in $\left(X, T^{*}\right)$. Then $\alpha$ is fuzzy supra pre $F_{\sigma}$ - set in $\left(X, T^{*}\right)$ and $\operatorname{pint}^{*}(\alpha)=0$ and hence $\alpha$ is a fuzzy supra pre $\sigma$ - nowhere dense set in $\left(X, T^{*}\right)$.

Remarks 3.7: If $A$ and $B$ are fuzzy supra pre $\sigma-$ nowhere dense sets in a fuzzy supra topological space $\left(X, T^{*}\right)$, then $A \vee B$ need not be a fuzzy supra pre $\sigma-$ nowhere dense set in $\left(X, T^{*}\right)$. For, consider the following example:

Example 3.8: Let $X=\{a, b, c\}$ be a set with a fuzzy supra topology $\left(X, T^{*}\right)$. Then the fuzzy sets $A=\left\{a_{.7}, b_{.6}, c_{.5}\right\}, B=\left\{a_{.4}, b_{.4}, c_{88}\right\}, c=$ $\left\{a_{.7}, b_{.6}, c_{.6}\right\}$

$T^{*}=\{0, A, B, C, A \vee B, B \vee C, B \wedge C, 1-$

Then

$A, 1-B, 1-C, 1-A \vee B, 1-B \vee C, 1-B \wedge$ C, 1$\}$

. Now, consider the fuzzy set $\alpha=[(1-B) \vee\{1-(A \vee B)\} \vee\{1-B \vee C)\}]$ and $\beta=[(1-A) \vee(1-C)]$ are fuzzy supra pre $F_{\sigma}-$ sets in $\left(X, T^{*}\right)$. Also pint $(\alpha)=0$ and $\operatorname{pint}^{*}(\beta)=0$. Therefore $\alpha$ and $\beta$ are fuzzy supra pre $\sigma-$ nowhere dense sets in $\left(X, T^{8}\right)$. Clearly $(\alpha \vee \beta)$ is a fuzzy supra pre $F_{\sigma}-$ set in $\left(X, T^{*}\right)$. On computation, $\operatorname{pint}^{*}(\alpha \vee \beta)=(B \wedge C) \neq 0, \quad$ implies that $(\alpha \vee \beta)$ is not a fuzzy supra pre $\sigma$ - nowhere dense set in $\left(X, T^{*}\right)$.

Proposition 3.9: In a fuzzy supra topological space $\left(X, T^{*}\right)$ a fuzzy set A is fuzzy supra pre $\sigma$-nowhere dense set in $\left(X, T^{*}\right)$ if and only if $1-A$ is a fuzzy supra pre dense and fuzzy supra pre $G_{\delta}-\operatorname{set}$ in $\left(X, T^{*}\right)$.

Proof: Let A be a fuzzy supra pre $\sigma-$ nowhere dense set in $\left(X, T^{*}\right)$. Then $A=\mathrm{V}_{i=1}^{\infty} A_{i}$, where $1-A_{i} \in T^{*}$ for $i \in I \quad$ and $\quad \operatorname{pint}^{*}(A)=0 . \quad$ Then $1-\operatorname{pint}^{*}(A)=1-0=1$ implies that $\quad p c l^{*}(1-A)=1$. Also
$\left(1-A_{i}\right) \in T^{*}{ }_{\text {, for }} i \in I$. Hence we have $(1-A)$ is a fuzzy supra pre dense and fuzzy supra pre $G_{\delta}-$ set in $\left(X, T^{*}\right)$.

Conversely, let A be a fuzzy supra pre dense and fuzzy supra pre $G_{\delta}-$ set in $\left(X, T^{*}\right)$. Then $A=\Lambda_{i=1}^{\infty}\left(A_{i}\right)$ where $\left(A_{i}\right) \in T^{*}, \quad$ for $\quad i \in I$. Now $(1-A)=1-\Lambda_{i=1}^{\infty}\left(A_{i}\right)=\mathrm{V}_{i=1}^{\infty}\left(1-A_{i}\right)$. Hence $1-A$ is a fuzzy supra pre $F_{\sigma}-$ set in $\left(X, T^{*}\right)$ and pint $^{*}(1-A)=1-p c l^{*}(A)=1-1=0$. [ Since $\mathrm{A}$ is a fuzzy supra pre dense]. Therefore $1-A$ is a fuzzy supra pre $\sigma$-nowhere dense set in $\left(X, T^{*}\right)$.

Proposition 3.10: If A is fuzzy supra pre dense set in $\left(X, T^{*}\right)$ such that $B \leq(1-A)$, where $\mathrm{B}$ is a fuzzy supra pre $F_{\sigma}-$ set in $\left(X, T^{*}\right)$, then B is a fuzzy supra pre $\sigma$-nowhere dense setin $\left(X, T^{*}\right)$.

Proof: Let A be a fuzzy supra pre dense set in $\left(X, T^{*}\right)$ such that $B \leq(1-A)$. Now $B \leq(1-A)$ implies that

$\operatorname{pint}^{*}(B) \leq \operatorname{pint}^{*}(1-A)=1-p c l^{*}(A)=$ $1-1=0$

and hence $\operatorname{pint}^{*}(B)=0$. Therefore B is a fuzzy supra pre $\sigma$-nowhere dense set in $\left(X, T^{*}\right)$.

Proposition 3.11: If A is a fuzzy supra pre $F_{\sigma}-_{\text {set }}$ and fuzzy supra pre nowhere dense set in $\left(X, T^{*}\right)$, then $\mathrm{A}$ is a fuzzy supra pre $\sigma$-nowhere dense set in $\left(X, T^{*}\right)$.

Proof: Now $\mathrm{A} \leq p c l^{*}(A)$ for any fuzzy set in $\left(X, T^{*}\right)$. Then, $\operatorname{pint}^{*}(A) \leq p \operatorname{pint} t^{*} p c l^{*}(A)$. Since $\mathrm{A}$ is a fuzzy supra pre nowhere dense set in $\left(X, T^{*}\right)$, pint ${ }^{*} p c l^{*}(A)=0 \quad$ and $\quad$ hence $\operatorname{pint}^{*}(A)=0$ and $\mathrm{A}$ is a fuzzy supra pre $F_{\sigma}$ - set implies that A is a fuzzy supra pre $\sigma$-nowhere dense set in $\left(X, T^{*}\right)$.

Definition 3.12: Let $\left(X, T^{*}\right)$ be a fuzzy supra topological space. A fuzzy set $\mathrm{A}$ in $\left(X, T^{*}\right)$ is called fuzzy supra pre $\sigma$-first category if $A=V_{i=1}^{\infty}\left(A_{i}\right)$ where $\left(A_{i}\right)^{\prime}$ s are fuzzy supra pre $\sigma$-nowhere dense sets in $\left(X, T^{*}\right)$. Any other fuzzy set in $\left(X, T^{*}\right)$ is said to be fuzzy supra pre $\sigma-$ second category in $\left(X, T^{*}\right)$.

$(1-A)=1-V_{i=1}^{\infty}\left(A_{i}\right)=\Lambda_{i=1}^{\infty}\left(1-A_{i}\right)$ where

\section{E.Poongothai \& G.Thangaraj,}


Definition 3.13: Let $A$ be a fuzzy supra pre $\sigma$-first category set in $\left(X, T^{*}\right)$. Then $1-A$ is called a fuzzy supra pre $\sigma$-residual set in $\left(X, T^{* 8}\right)$.

Definition 3.14: A fuzzy supra topological space $\left(X, T^{*}\right)$ is called fuzzy supra pre $\sigma$-first category if the fuzzy set $1_{X}$ is a fuzzy supra pre $\sigma$-first category set in $\left(X, T^{*}\right)$. That is, $1_{X}=V_{i=1}^{\infty}\left(A_{i}\right)$ where $\left(A_{i}\right)$ 's are fuzzy supra pre $\sigma$-nowhere dense sets in $\left(X, T^{*}\right)$. Otherwise, $\left(X, T^{*}\right)$ will be called a fuzzy supra pre $\sigma-$ second category space.

Proposition 3.15: If $A$ is a fuzzy supra pre $\sigma$-first category set in $\left(X, T^{*}\right)$, then there is a fuzzy supra pre $F_{\sigma}$-set $B$ in $(\mathrm{X}, \mathrm{T})$ such that $A \leq B$.

Proof: Let $A$ be a fuzzy supra pre $\sigma$-first category set in $\left(X_{,} T^{8}\right)$. Then $A=V_{i=1}^{\infty}\left(A_{i}\right)$, where $\left(A_{i}\right)$ 's are fuzzy supra pre $\sigma$-nowhere dense sets in $\left(X, T^{*}\right)$. Now $\left[1-p \mathrm{cl}^{*}\left(A_{i}\right)\right]^{\prime} \mathrm{s} \quad(\mathrm{i}=1$ to $\infty)$ are fuzzy supra pre open sets in $\left(X, T^{*}\right)$. Then $C=\Lambda_{i=1}^{\infty}\left(1-p c l^{*}\left(A_{i}\right)\right)$ is a fuzzy supra pre $G_{\delta}$-set in $\left(X, T^{*}\right) \quad$ and $1-C=1-\left[\wedge_{i=1}^{\infty}\left(1-p c l^{*}\left(A_{i}\right)\right)\right]=$ $\left[\mathrm{V}_{i=1}^{\infty} p \mathrm{cl}^{*}\left(A_{i}\right)\right]$.

Now $\quad\left(A_{i}\right) \leq p c l^{*}\left(A_{i}\right)_{3} \quad$ implies that $\mathrm{V}_{i=1}^{\infty}\left(A_{i}\right) \leq\left[\mathrm{V}_{i=1}^{\infty} p c l^{*}\left(A_{i}\right)\right] \quad$. Hence $A=\mathrm{V}_{i=1}^{\infty}\left(A_{i}\right) \leq\left[\mathrm{V}_{i=1}^{\infty} p \mathrm{cl}^{8}\left(A_{i}\right)\right]=[1-B]$. That is, $A \leq[1-B]$ and $[1-B]$ is a fuzzy supra pre $F_{\sigma}$-set in $\left(X, T^{*}\right)$. Let $B=[1-C]$. Hence, if $A$ is a fuzzy supra pre $\sigma$-first category set in $\left(X_{y} T^{*}\right)$, then there is a fuzzy supra pre $F_{\sigma}$-set $B$ in $(\mathrm{X}, \mathrm{T})$ such that $A \leq B$.

Proposition 3.16: If $A$ is a fuzzy supra pre $\sigma$-first category set in $\left(X, T^{*}\right)$, then there is a fuzzy supra pre $F_{\sigma}$-set $B$ in $\left(X, T^{*}\right)$ such that $A \leq B \leq p c l^{*}(A)_{3}$ where $B$ is a fuzzy supra pre $F_{\sigma}$-set in $\left(X, T^{8}\right)$.

Proof: Let $A$ be a fuzzy supra pre $\sigma$-first category set in $\left(X_{,} T^{*}\right)$. Then $A=\mathrm{V}_{i=1}^{\infty}\left(A_{i}\right)$, where $\left(A_{i}\right)$ 's are fuzzy supra pre $\sigma$-nowhere dense sets in $\left(X, T^{\star}\right)$. Now $\left[1-p \mathrm{cl}^{*}\left(A_{i}\right)\right]$ 's $\quad(\mathrm{i}=1$ to $\infty)$ are fuzzy supra pre open sets in $\left(X, T^{*}\right)$. Then
$B=\wedge_{i=1}^{\infty}\left(1-p c l^{*}\left(A_{i}\right)\right)$ is a fuzzy supra pre $G_{\delta}$-set in $\left(X, T^{*}\right) \quad$ and $1-B=1-\left[\Lambda_{i=1}^{\infty}\left(1-p d^{b}\left(A_{i}\right)\right)\right]=$

$\left[V_{i=1}^{\infty} p d l^{*}\left(A_{i}\right)\right]$.

Now

$A=V_{i=1}^{\infty}\left(A_{i}\right) \leq\left[V_{i=1}^{\infty} p c l^{*}\left(A_{i}\right)\right]=[1-B]$.

That is, $A \leq[1-C] \leq p c l^{*}(A)$ and $[1-A]$ is a fuzzy supra pre $F_{\sigma}$-set in $\left(X, T^{8}\right)$. Let $B=[1-C]$. Hence, if $A$ is a fuzzy supra pre $\sigma$-first category set in $\left(X, T^{*}\right)$, then there is a fuzzy supra pre $F_{\sigma}$-set $B$ in $\left(X, T^{*}\right)$ such that $A \leq B \leq p \mathrm{cl}^{*}(A)$, where $B$ is a fuzzy supra pre $F_{\sigma}$-set in $\left(X_{,} T^{8}\right)$.

Proposition 3.17: If $A$ is a fuzzy supra pre closed set in a fuzzy supra topological space $\left(X, T^{*}\right)$ and if $\operatorname{pint}^{*}(A)=0$, then $A$ is a fuzzy supra pre $\sigma-$ nowhere dense set in $\left(X, T^{8}\right)$.

Proof: Let $A$ be a fuzzy supra pre closed set in $\left(X, T^{*}\right)$. Then we have $p \mathrm{cl}^{*}(A)=A$. Now $\operatorname{pint}^{*}\left[p c l^{*}(A)\right]=\operatorname{pint}^{*}(A)$ and pint ${ }^{*}(A)=$ 0 , implies that $A$ is a fuzzy supra pre $\sigma$ - nowhere dense set in $\left(X, T^{*}\right)$.

\section{FUZZY SUPRA PRE $\sigma$-BAIRE SPACE}

Definition 4.1: Let $\left(X, T^{*}\right)$ be a fuzzy supra topological space. Then $\left(X, T^{8}\right)$ is called a fuzzy supra pre $\sigma$-Baire Space if $\operatorname{pint}^{*}\left(\mathrm{~V}_{i=1}^{\infty}\left(A_{i}\right)\right)$ where $\left(A_{i}\right)$ 's are fuzzy supra pre $\sigma$-nowhere dense sets in $\left(X, T^{*}\right)$.

Example 4.2: Let $X=\{a, b, c\}$ be a set with a fuzzy supra topology $\left(X, T^{*}\right)$. Then the fuzzy sets $A=\left\{a_{.7}, b_{.6}, c_{.7}\right\}, B=\left\{a_{.6}, b_{8}, c_{8}\right\}_{,} c=$ $\left\{a_{.7}, b_{5,}, c_{.9}\right\}$

$T^{*}=\{0, A, B, C, A \vee B, A \vee C, B \vee C, B \wedge$

Then

$C_{,} 1-A_{,} 1-B_{,} 1-C_{,} 1-A \vee B, 1-B \vee$

$C, 1-B \wedge C, 1\}$

- Now, consider the fuzzy set $\alpha=(1-A \vee B) \vee(1-B \vee C) \vee(1-B \wedge C)$

in $\left(X, T^{8}\right)$. Then $\alpha$ is fuzzy supra pre $F_{\sigma}-$ set in

\section{E.Poongothai \& G.Thangaraj,}


$\left(X, T^{*}\right)$ and $\operatorname{pint}^{*}(\alpha)=0$ and hence $\alpha$ is a fuzzy supra pre $\sigma$ - nowhere dense setin $\left(X, T^{8}\right)$.

$\beta=(1-B) \vee(1-A \vee C) \vee(1-B \vee(A \wedge$

C))

and $\operatorname{pint}^{*}(\beta)=0$ and hence $\beta$ is a fuzzy supra pre $\sigma-$ nowhere dense set in $\left(X, T^{*}\right)$. Then $\alpha$ and $\beta$ are fuzzy supra pre $\sigma$-nowhere dense set in $\left(X, T^{*}\right)$ and also pint ${ }^{*}(\alpha \vee \beta)=0$ and therefore $\left(X, T^{*}\right)$ is a fuzzy supra pre $\sigma$-Baire Space.

Proposition 4.3: Let $\left(X, T^{*}\right)$ be a fuzzy supra topological space. Then the following are equivalent:

$\left(X, T^{*}\right)$ is a fuzzy supra pre $\sigma-$ Baire Space.

pint $^{*}(A)=0$ for every fuzzy supra pre $\sigma-$ first category set $\mathrm{A}$ in $\left(X, T^{*}\right)$.

$p c l^{*}(B)=1$ for every fuzzy supra pre $\sigma$-residual set B in $\left(X, T^{*}\right)$.

Proof: (1) $\Rightarrow$ (2). Let A be a fuzzy supra pre $\sigma-$ first category set $\mathrm{A}$ in $\left(X, T^{*}\right)$. Then $A=\left(\mathrm{V}_{i=1}^{\infty}\left(A_{i}\right)\right)$ where $\left(A_{i}\right)$ 's are fuzzy supra pre $\sigma-$ nowhere dense sets in $\left(X, T^{8}\right)$. Then, we have $\operatorname{pint}^{*}(A)=\operatorname{pint}^{*}\left(\mathrm{~V}_{i=1}^{\infty}\left(A_{i}\right)\right)$.

Since $\left(X, T^{*}\right)$ is a fuzzy supra pre $\sigma-$ Baire Space, pint $^{*}\left(\vee_{i=1}^{\infty}\left(A_{i}\right)\right)=0$. Hence pint ${ }^{*}(A)=0$ for any fuzzy supra pre $\sigma-$ first category set A in $\left(X, T^{*}\right)$.

(2) $\Rightarrow$ (3). Let $B$ be a fuzzy supra pre $\sigma$-residual set B in $\left(X, T^{*}\right)$. Then $(1-B)$ is a fuzzy supra pre $\sigma-$ first category set $\mathrm{B}$ in $\left(X, T^{*}\right)$. By hypothesis, pint $^{*}(1-B)=0$. Then $1-p c l^{*}(B)=0$. Hence $p c l^{*}(B)=1$ for any fuzzy supra pre $\sigma-$ residual set B in $\left(X, T^{*}\right)$.

(3) $\Rightarrow$ (1). Let A be a fuzzy supra pre $\sigma$-first category set $\mathrm{A}$ in $\left(X, T^{*}\right)$. Then $A=\left(\mathrm{V}_{i=1}^{\infty}\left(A_{i}\right)\right)$ where $\left(A_{i}\right)^{\prime}$ 's are fuzzy supra pre $\sigma$-nowhere dense sets in $\left(X, T^{*}\right)$. Now A is a fuzzy supra pre $\sigma$-first category set in $\left(X, T^{*}\right)$ implies that $(1-A)$ is a fuzzy supra pre $\sigma-$ residual set in $\left(X, T^{*}\right)$. By hypothesis, we have $p c l^{*}(1-A)=1$. Then $1-$ pint $^{*}(A)=1$. Hence $\operatorname{pint}^{*}(A)=0$. That is, $\operatorname{pint}^{*}\left(\vee_{i=1}^{\infty}\left(A_{i}\right)\right)=0$ where $A_{i}^{\prime} S$ are fuzzy supra pre $\sigma$-nowhere dense sets in $\left(X, T^{*}\right)$. Hence $\left(X, T^{*}\right)$ is a fuzzy supra pre $\sigma$-Baire Space.

Proposition 4.4: If $p c l^{*}\left(\Lambda_{i=1}^{\infty}\left(A_{i}\right)\right)=1$, where $\left(A_{i}\right)$ 's are fuzzy supra pre dense and fuzzy supra pre $G_{\delta}$ - sets in $\left(X, T^{*}\right)$, then $\left(X, T^{*}\right)$ is a fuzzy supra pre $\sigma$-Baire Space.

Proof: Now $p c l^{*}\left(\Lambda_{i=1}^{\infty}\left(A_{i}\right)\right)=1$ implies that $1-p c l^{*}\left(\wedge_{i=1}^{\infty}\left(A_{i}\right)\right)=0$. Then we have $\operatorname{pint}^{*}\left(1-\Lambda_{i=1}^{\infty}\left(A_{i}\right)\right)=0$, which implies that pint $^{*}\left(\mathrm{~V}_{i=1}^{\infty}\left(1-A_{i}\right)\right)=0$. Let $B_{i}=1-A_{i}$. Then pint ${ }^{*}\left(\mathrm{~V}_{i=1}^{\infty}\left(B_{i}\right)\right)=0$. Since $A_{i}$ is a fuzzy supra pre dense and fuzzy supra pre $G_{\delta}-$ set in $\left(X, T^{*}\right)$, by proposition $3.9,1-A_{i}$ is a fuzzy supra $\sigma$-nowhere dense set in $\left(X, T^{*}\right)$. Hence pint ${ }^{*}\left(\mathrm{~V}_{i=1}^{\infty}\left(B_{i}\right)\right)=0$, where $\left(B_{i}\right)$ 's are fuzzy supra $\sigma$-nowhere dense set in $\left(X, T^{*}\right)$. Therefore $\left(X, T^{*}\right)$ is a fuzzy supra $\sigma-$ Baire Space.

Proposition 4.5: If the fuzzy supra topological space $\left(X, T^{*}\right)$ is a fuzzy supra pre $\sigma-$ Baire Space, then $\left(X, T^{*}\right)$ is a fuzzy supra pre $\sigma-$ second category space.

Proof: Let $\left(X, T^{*}\right)$ is a fuzzy supra pre $\sigma$-Baire Space. Then pint ${ }^{*}\left(\mathrm{~V}_{i=1}^{\infty}\left(A_{i}\right)\right)=0$ where $\left(A_{i}\right)$ 's are fuzzy supra pre $\sigma$-nowhere dense set in $\left(X, T^{*}\right)$. Then $\mathrm{V}_{i=1}^{\infty}\left(A_{i}\right) \neq 1_{X}$ [otherwise, $V_{i=1}^{\infty}\left(A_{i}\right)=1_{X}$ implies that $\operatorname{pint}^{*}\left(\mathrm{~V}_{i=1}^{\infty}\left(A_{i}\right)\right)=\operatorname{int}^{*} 1_{X}=1_{X^{s}} \quad$ which implies that $0=1$, a contradiction]. Hence $\left(X, T^{*}\right)$ is a fuzzy supra pre $\sigma$-second category space.

Proposition 4.6: If the fuzzy supra topological space $\left(X, T^{*}\right)$. If $\Lambda_{i=1}^{\infty}\left(A_{i}\right) \neq 0$, where $\left(A_{i}\right)$ 's are fuzzy supra pre dense and fuzzy supra pre $G_{\delta}-\operatorname{set}$ in $\left(X, T^{*}\right)$, then $\left(X, T^{*}\right)$ is a fuzzy supra pre $\sigma-$ second category space.

Proof: Now $\Lambda_{i=1}^{\infty}\left(A_{i}\right) \neq 0$ implies that $1-\left(\Lambda_{i=1}^{\infty}\left(A_{i}\right)\right) \neq 1-0=0$. Then we have $\left(\mathrm{V}_{i=1}^{\infty}\left(1-A_{i}\right)\right) \neq 1$. Since $A_{i}$ is a fuzzy supra pre dense and fuzzy supra $G_{\delta}-$ set in $\left(X, T^{*}\right)$, by proposition $3.9,\left(1-A_{i}\right)$ is a fuzzy supra pre $\sigma-$ nowhere dense set in $\left(X, T^{*}\right)$. Hence

\section{E.Poongothai \& G.Thangaraj,}


$\left(\mathrm{V}_{i=1}^{\infty}\left(1-A_{i}\right)\right) \neq 1$, where $\left(1-A_{i}\right)$ 's are fuzzy supra pre $\sigma$-nowhere dense set in $\left(X, T^{*}\right)$. Hence $\left(X, T^{*}\right)$ is not a fuzzy supra pre $\sigma-$ first category space. Therefore $\left(X, T^{*}\right)$ is a fuzzy supra pre $\sigma-$ second category space.

Proposition 4.7: If the fuzzy supra topological space $\left(X, T^{8}\right)$ is a fuzzy supra pre $\sigma-$ first category space, then $\left(X, T^{*}\right)$ is not a fuzzy supra pre $\sigma-$ Baire Space.

Proof: Let the fuzzy supra topological space $\left(X, T^{*}\right)$ is a fuzzy supra pre $\sigma$ - first category space. Then $V_{i=1}^{\infty}\left(A_{i}\right)=1_{X}$, where $\left(A_{i}\right)$ 's are fuzzy supra pre $\sigma-$ nowhere dense sets in $\left(X, T^{*}\right)$. Now pint $^{*}\left(V_{i=1}^{\infty}\left(A_{i}\right)\right)=\operatorname{pint}^{*}\left(1_{X}\right)=1 \neq 0$. Hence by definition, $\left(X, T^{*}\right)$ is not a fuzzy supra pre $\sigma-$ Baire Space.

Proposition 4.8: If the fuzzy supra topological space $\left(X, T^{*}\right)$ is a fuzzy supra pre $\sigma-$ Baire Space and if $V_{i=1}^{\infty}\left(A_{i}\right)=1$, then there exists atleast one fuzzy supra pre $F_{\sigma}-\operatorname{set} A_{i} \quad$ such that $\operatorname{pint}^{*}\left(A_{i}\right) \neq 0$.

Proof: Suppose that pint ${ }^{*}\left(A_{i}\right)=0$, for $i=1$ to $\infty_{\text {, }}$ where $\left(A_{i}\right)$ 's are fuzzy supra pre $\sigma-$ nowhere dense sets in $\left(X, T^{*}\right)$. Then $V_{i=1}^{\infty}\left(A_{i}\right)=1$. Implies that pint $^{*}\left[\mathrm{~V}_{i=1}^{\infty}\left(A_{i}\right)\right]=$ pint $[1]=1 \neq 0$, a contradiction to $\left(X, T^{*}\right)$ being a fuzzy supra pre $\sigma-$ Baire Space. Hence $\operatorname{pint}^{*}\left(A_{i}\right) \neq 0$, for at least one fuzzy supra pre $F_{\sigma}-\operatorname{set} A_{i}$ in $\left(X, T^{*}\right)$.

\section{REFERENCES}

[1]. Zadeh L.A., Fuzzy Sets, 1965,Int. Contr. 8, 338-353.

[2]. Abd. El-Monsef M.F., and Ramadan A.E. On fuzzy supra topological spaces, Indian J.Pure. Appl.Math 1987, 18(4) 322-329.

[3]. Bin Shahna A.S, 1991, On fuzzy strongly semi continuity and fuzzy precontinuity, Fuzzy sets and systems 44.308-330.

[4]. Singal M.K and Prakash.N,1986, Fuzzy preopen sets and fuzzy preseparation axioms, Bull.Call. Math.Soc. 78,57-69.

[5]. Hakeem A. Othman, 2011, On fuzzy sp-open sets, Hindawi Publishing Corporation, Advances in Fuzzy Systems, 1-5.

[6]. Selvi.T and Punitha Dharani.A,2012, Some new class of nearly closed and open sets, Asian Journal of current Engineering and Maths. 1 (5) 305-307.

[7]. Hakeem A. Othman, 2016,0n fuzzy Supra-preopen sets, Annals of Fuzzy Mathematics and Informatics 12(3) 361-371.
[8]. Poongothai. E and Thangaraj.G,2017, Fuzzy setting on supra sigma baire spaces, Asian journal of Applied Research (communicated)

[9]. Chang C.L., Fuzzy topological spaces,1968, J. Math. Anal. And Appl. 24 , 182-190.

[10]. Mashhour A.S.Allan A.A., Mahmoud F.S and Khedr F.H.,1983, On supra topological space, Indian J.Pure Appl. Math. 14(4) 502-510.

\section{E.Poongothai \& G.Thangaraj,}

